\title{
MOTIVASI PEMBERIAN SUSU FORMULA PADA BAYI BARU LAHIR DI RUMAH SAKIT IBU DAN ANAK BADRUL AINI MEDAN TAHUN 2015
}

\author{
Dina Indarsita, Yufdel, Nurul Yasintha \\ Jurusan Keperawatan Poltekkes Kemenkes Medan
}

\begin{abstract}
Abstrak
Susu formula adalah susu yang sesuai dan bisa diterima oleh sistem tubuh bayi. Motivasi adalah keinginan yang terdapat pada seorang individu yang merangsangnya untuk melakukan tindakan-tindakan. Sekitar 57\% ibu-ibu dianjurkan untuk memberikan susu formula pada minggu pertama setelah kelahiran dan ibu yang memberikan susu formula di antaranya disebabkan oleh adanya indikasi pada bayi dan ibu. Tujuan penelitian ini adalah untuk mengetahui Motivasi Dalam Pemberian Susu Formula Pada Bayi Baru Lahir Di Rumah Sakit Ibu dan Anak Badrul Aini Medan Tahun 2015. Penelitian ini bersifat deskritif dengan desain cross sectional, pengumpulan data menggunakan kuesioner dan populasi dalam penelitian ini adalah seluruh Bidan yang berada di Rumah Sakit Ibu dan Anak Badrul Aini Medan Tahun 2015, dengan jumlah 20 bayi menggunakan teknik total Sampling. Pengolahan data dilakukan dengan cara editing, coding, tabulating, scoring dan analisa distribusi frekuensi. Hasil penelitian didapatkan bahwa $75.0 \%$ motivasi bidannya baik, mayoritas (35.0\%) umur 20-24 tahun, (80.0\%) yang berpendidikan DIII, (90.0\%) yang berstatus karyawan, $(100.0 \%)$ cara pemberian susu formula dalam kategori baik. Dari hasil penelitian ini dapat disimpulkan bahwa motivasi bidan baik yang dipengaruhi oleh motivasi instrinsik. Selanjutnya diharapkan pada tenaga kesehatan khususnya bidan. Lebih cerdas dalam pemberian susu formula terutama dalam memenuhi kebutuhan bayi.
\end{abstract}

Kata kunci : Motivasi, Pemberian Susu Formula

\section{PENDAHULUAN}

Menurut Worl Health Organization (WHO) pada tahun 2012, susu formula adalah susu yang sesuai dan bisa diterima oleh sistem tubuh bayi. Susu formula yang baik tidak menimbulkan gangguan saluran pencernaan seperti diare, muntah, atau kesulitan buang air besar. Demikian juga dengan gangguan lainnya seperti batuk, sesak, dan gangguan kulit (Siti. 2012.hlm.18).

Hasil Penelitian Depkes RI (2012) di Bogor menjelaskan bahwa anak yang diberi ASI Ekslusif tidak ada yang menderita gizi buruk. Data untuk Penulisan yang sama menunjukkkan bahwa 57\% ibu-ibu dianjurkan oleh bidan untuk memberikan susu formula pada minggu pertama setelah kelahiran dan ibu yang memberikan susu formula dari iklan promosi sebesar 8,7\%. Sedangkan lebih dari $25 \%$ ibu-ibu mengatakan menerima susu formula melalui Rumah Sakit atau Rumah Bersalin, sekitar 9,5\% ibu menerima hadiah dari perusahaan susu formula, temuan-temuan penting lainnya dari study tersebut adalah $14,8 \%$ bidan menyatakan setuju untuk memberikan susu formula pada bayi baru lahir. Selain melalui iklan di media dan promosi dipertokoan, pada produsen susu formula juga aktif promosi di Rumah Sakit dan Klinik Bersalin melalui bidan, sampel susu kaleng secara gratis diberikan kepada pasien. Ibu yang pulang dari Rumah Sakit banyak yang diberi oleh susu kaleng gratis.Kini semakin banyak ibu-ibu yang tidak percaya diri dengan manfaat dari kandunganASI akibat pengaruh iklan yang menyediakan kandungan zat gizi terdapat dalam susu formula (http://wikipedia.Bidan. 2012). Berbagai Penulisan menyatakan pemberian ASI ekslusif di tempat pelayanan Rumah Sakit atau Rumah Bersalin sangat tergantung Bidan. Hal ini disebabkan bidan adalah orang yang pertama yang membantu dan memotivasi ibu bersalin melakukan pemberian ASI ekslusif tersebut. Pentingnya Rumah Sakit atau Rumah Bersalin dalam pengambilan keputusan tentang pemberian ASI Ekslusif menurun dari $8 \%$ menjadi 3,7\%. Pemberian ASI ekslusif selama 6 bulan menurun dari 42,2\% menjadi 39,7\%, sedangkan penggunaan susu formula lebih tinggi tiga kali lipat dari $10,8 \%$ menjadi $32,5 \%$. Diasumsikan bahwa Bidan mempunyai peranan dalam upaya pemberian susu formula (Jurdawanto .2012.hlm.38).

Rumah Sakit sebagai salah satu prasarana kesehatan yang memberikan pelayanan kesehatan kepada masyarakat, memiliki peran yang sangat strategis dalam mempercepat peningkatan derajat kesehatan masyarakat.Oleh karena itu, rumah sakit dituntut untuk memberikan pelayanan yang bermutu sesuai dengan standar yang ditetapkan dan dapat menjangkau seluruh lapisan masyarakat dan bidan sebagai motivasi dalam 
memberi informasi kepada ibu yang melahirkan, maka diharapkan bidan meningkatkan pengetahuan dan berperan aktif dalam meningkatkan kesadaran ibu dalam penggunaan ASI ekslusif pada bayinya (Satrianegara.2012. hlm.63)

\section{RUMUSAN MASALAH}

Rumusan masalah penelitian ini adalah Bagaimana Motivasi Pemberian Susu Formula pada Bayi Baru Lahir di Rumah Sakit Ibu dan Anak Badrul Aini Medan tahun 2015.

\section{TUJUAN PENELITIAN}

1. Untuk mengetahui Motivasi Pemberian Susu Formula pada Bayi Baru Lahir di Rumah Sakit Ibu dan Anak Badrul Aini Medan tahun 2015.

2. Untuk Mengetahui Motivasi Instrinsik Bidan dalam Pemberian Susu Formula pada Bayi Baru Lahir di Rumah Sakit Ibu dan Anak Badrul Aini Medan tahun 2015.

3. Untuk Mengetahui Motivasi Ekstrinsik Bidan dalam Pemberian Susu Formula pada Bayi Baru Lahir di Rumah Sakit Ibu dan Anak Badrul Aini Medan tahun 2015.

4. Untuk Mengetahui Pemberian Susu Formula pada Bayi Baru Lahir di Rumah Sakit Ibu dan Anak Badrul Aini Medan tahun 2015.

\section{MANFAAT PENELITIAN}

1) Bagi Rumah Sakit

Merupakan sebagai bahan masukan kepada management rumah sakit untuk lebih memberikan pelatihan-pelatihan tentang bagaimana mengatasi penurunan terjadinya angka pemberian susu formula.

2) Bagi Pelayanan

Merupakan sebagai bahan pertimbangan kepada setiap tenaga kesehatan khususnya bidan agar lebih mengutamakan IMD sebelum memberikan susu formula pada bayi baru lahir.

3) Perkembangan ilmu kebidanan

Merupakan sebagai bidang perkembangan ilmu kebidanan yang selalu memiliki teori terbaru khususnya dalam asuhan Neonatus, Balita dan anak prasekolah.

\section{METODE PENELITIAN}

Penelitian ini bersifat deskritif dengan desain cross sectional yaitu rancangan penelitian yang bertujuan untuk menerangkan atau menggambarkan masalah penelitian yang terjadi berdasarkan karakteristik tempat, waktu, umur, jenis kelamin, sosial, ekonomi, pekerjaan, status perkawinan, cara hidup (pola hidup), dan lain-lain (Hidayat. 2010. Hlm.53).

\section{POPULASI DAN SAMPEL}

Populasi penelitian ini adalah seluruh bidan yang berada di RS Ibu dan Anak Badrul Aini Medan Tahun 2015, berjumlah sekitar 20 bidan dan sampel dalam penelitian ini adalah total sampling dimana pengambilan sampel dilakukan dengan mengambil jumlah keseluruhan responden yang berada di tempat Penulisan tersebut (Notoatmodjo. 2010. Hlm.125).

\section{TEMPAT DAN WAKTU PENELITIAN}

Penelitian ini akan dilakukan di Rumah Sakit Ibu dan Anak Badrul Aini Medan dengan pertimbangan ingin mengetahui motivasi bidan dalam pemberian susu formula pada Bayi Baru Lahir, belum pernah dilakukan Penelitian sebelumnya, populasi dan sampel yang yang dibutuhkan mecukupi untuk dijadikan responden, serta waktu dan biaya yang dapat dijangkau oleh penulis. Penelitian dilaksanakan pada bulan November 2014 sampai Mei 2015.

\section{ALAT PENGUMPULAN DATA}

Pengumpulan data akan dilakukan dengan menggunakan kuesioner yang disusun oleh penulis dengan mengacu kepada kerangka konsep dan tinjauan pustaka meliputi Motivasi Bidan Dalam Pemberian Susu Formula Pada Bayi Baru Lahir di Rumah Sakit Ibu Dan Anak Badrul Aini Medan Tahun 2015. Dimana terdapat 20 soal dengan pilihan jawaban 'Ya' dan 'Tidak'. Kuesioner ini menggunakan checklist atau daftar cek yang merupakan daftar yang berisi pernyataan yang akan diamati dan responden memberikan jawaban dengan memberikan cek $(\sqrt{ })$ sesuai dengan hasilnya yang diinginkan.

\section{PENGOLAHAN DATA}

Data yang dikumpulkan berupa jawaban dari setiap pertanyaan kuesioner yang akan diolah dengan langkahlangkah sebagai berikut :

1. Editing (Edit)

Editing adalah upaya untuk memeriksa kembali kebenaran data yang diperoleh atau dikumpulkan.Editing dapat dilakukan pada tahap pengumpulan data atau setelah data terkumpul.

2. Coding (Kode)

Coding merupakan kegiatan pemberian kode numerik (angka) terhadap data yang terdiri atas beberapa kategori. Data yang telah diedit dirubah ke dalam bentuk angka (kode) nama responden dirubah menjadi nomor responden 01, 02, 03, dan seterusnya.

3. Tabulating (Tabel)

Adalah kegiatan memasukkan data yang telah dikumpulkan ke dalam master tabel atau database komputer, kemudian membuat distribusi frekuensi sederhana. 
4. Scoring (Skor)

Memberikan skor terhadap jawaban-jawaban responden pada kuesioner untuk penilaian Motivasi Bidan Dalam Pemberian Susu Formula Pada BBL .

Sebelumnya menentukan kategori sangat setuju, setuju, tidak setuju, dan sangat tidak setuju sebagai tolak ukur yang akan dijadikan pemantauan ukuran.

Penentuan skoring dengan cara :

Untuk pertanyaan bila jawaban benar diberi nilai: 1, dan bila jawaban salah diberi nilai: 0 menggunakan Skala Guttman (Hidayat. 2007. Hlm.103).

Skor tertinggi adalah nilai jawaban yang

benar di kali jumlah soal, yaitu :1×20=20

Skor terendah adalah nilai jawaban yang

salah di kali jumlah soal, yaitu : 0x20=0

Untuk menentukan rentang dan interval digunakan rumus :

$$
\begin{aligned}
& \mathrm{R}=\mathrm{X}_{\max }-\mathrm{X}_{\min } \\
& P=\frac{R}{\text { Jumlah Kategori }}
\end{aligned}
$$

Keterangan :

$\mathrm{R}=$ Rentang

$\mathrm{X}_{\max }=$ Jumlah skor untuk jawaban benar: 1 dikali jumlah soal

$\mathrm{X}_{\min }=$ Jumlah skor untuk jawaban salah: 0 dikali jumlah soal

$\mathrm{P}=$ Interval (Sudjana, 2005:47)

Dari rumus dapat diketahui :

$\mathrm{Xmax}=1 \times 20=20$

$X \min =0 \times 20=0$

$\mathrm{R} \quad=20-0=20$

$\mathrm{P} \quad=20 \div 2=10$

Dari data tersebut dapat di simpulkan :

a. Baik apabila mendapat skor $11-20$

b. Kurang baik apabila mendapat skor $0-10$

\section{ANALYSIS (ANALISIS)}

Analisa data dilakukan secara deskriptif dengan melihat persentase data terkumpul dan disajikan dalam bentuk tabel distribusi frekuensi (Hidayat, $2011 ; 121$ ).

\section{HASIL PENELITIAN}

1. Karakteristik Responden

Karakteristik responden pada penelitian ini dengan 20 responden meliputi umur, pendidikan, dan pekerjaan.
Tabel 1. Karakterisik Responden di Rumah Sakit Ibu dan Anak Badrul Aini Medan Tahun 2015

\begin{tabular}{ccc}
\hline Karakteristik & Frekuensi & $\begin{array}{c}\text { Persentase } \\
(\%)\end{array}$ \\
\hline Umur & & 35 \\
$20-24$ & 6 & 30 \\
$25-29$ & 4 & 20 \\
$30-34$ & 1 & 5 \\
$35-39$ & 2 & 10 \\
$40-44$ & 20 & 100 \\
Jumlah & & 10 \\
DI & 2 & 80 \\
DIII & 16 & 10 \\
DIV & 2 & 100 \\
Pumlah & & \\
Jumdidikan & 20 & 90 \\
Karyawan & 18 & 10 \\
Kepala Ruangan & 2 & 100 \\
Jumlah & 20 &
\end{tabular}

2. Motivasi bidan dalam pemberian susu formula di Rumah Sakit Ibu dan Anak Badrul Aini Medan Tahun 2015.

Motivasi dalam pemberian susu formula di Rumah Sakit Ibu dan Anak Badrul Aini Medan, dilihat dari hasil jawaban responden yang meliputi motivasi instrinsik, motivasi ekstrinsik dan pemberian susu formula. Lebih jelasnya dapat dilihat pada tabel 2 .

Tabel 2.Distribusi Frekuensi Motivasi bidan dalam Pemberian Susu Formula pada Bayi Baru Lahir di Rumah Sakit Badrul Aini Medan

\begin{tabular}{|c|c|c|}
\hline Motivasi bidan & Frekuensi & Presentase \% \\
\hline Baik & 15 & 75 \\
\hline Kurang & 5 & 25 \\
\hline Jumlah & 20 & 100 \\
\hline
\end{tabular}
Tahun 2015

Berdasarkan tabel di atas, dapat dilihat motivasi nya mayoritas baik sebanyak 15 orang $(75,0 \%)$ dan minoritas kurang sebanyak 5 orang $(25,0 \%)$.

3. Motivasi Instrinsik Bidan dalam Pemberian Susu Formula di Rumah Sakit Ibu dan Anak Badrul Aini Medan Tahun 2015

Tabel 3. Distribusi Frekuensi Motivasi Instrinsik Bidan dalam Pemberian susu formula pada Bayi Baru Lahir di Rumah Sakit Badrul Aini Medan Tahun 2015

\begin{tabular}{ccc}
\hline Motivasi Intrinsik & Frekuensi & $\begin{array}{c}\text { Presentase } \\
\text { \% }\end{array}$ \\
\hline Baik & 18 & 90 \\
Kurang & 2 & 10 \\
\hline Jumlah & 20 & 100 \\
\hline
\end{tabular}


Berdasarkan tabel di atas, dapat dilihat motivasi instrinsik mayoritas baik sebanyak 18 orang $(90 \%)$ dan kurang sebanyak 2 orang $(10 \%)$.

Tabel 4.Distribusi Frekuensi Motivasi Instrinsik Bidan dalam pemberian susu formula pada bayi baru lahir berdasarkan jawaban di Rumah Sakit Badrul Aini Medan Tahun 2015

\begin{tabular}{|c|c|c|c|c|c|c|c|}
\hline \multirow{3}{*}{ No } & \multirow{3}{*}{ Pernyataan } & \multicolumn{4}{|c|}{ Jawaban } & \multirow{2}{*}{\multicolumn{2}{|c|}{ Jumlah }} \\
\hline & & \multicolumn{2}{|c|}{ ya } & \multicolumn{2}{|c|}{ Tidak } & & \\
\hline & & $\mathrm{f}$ & $\%$ & $\mathrm{~F}$ & $\%$ & $\mathrm{~F}$ & $\%$ \\
\hline 1 & $\begin{array}{l}\text { Bidan memberikan susu } \\
\text { formula kepada bayi karena } \\
\text { Air Susu Ibu(ASI) belum } \\
\text { keluar }\end{array}$ & 28 & 50 & 28 & 50 & 20 & 100 \\
\hline 2 & $\begin{array}{l}\text { Bidan memberikan susu } \\
\text { formula kepada bayi karena } \\
\text { puting susu ibu terbenam }\end{array}$ & 54 & 96,4 & 2 & 3,6 & 20 & 100 \\
\hline 3 & $\begin{array}{l}\text { Bidan memberikan susu } \\
\text { formula kepada bayi karena } \\
\text { ASI ibu belum mencukupi } \\
\text { kebutuhan bayi }\end{array}$ & 24 & 42,9 & 32 & 57,1 & 20 & 100 \\
\hline 4 & 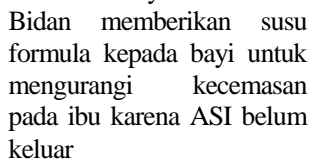 & 11 & 19,6 & 45 & 80,4 & 20 & 100 \\
\hline 5 & $\begin{array}{l}\text { Bidan memberikan susu } \\
\text { formula kepada bayi karena } \\
\text { kebutuhan bayi masih belum } \\
\text { mencukupi. }\end{array}$ & 38 & 67,9 & 18 & 32,1 & 20 & 100 \\
\hline
\end{tabular}

4. Motivasi Ekstrinsik Bidan dalam Pemberian Susu Formula di Rumah Sakit Ibu dan Anak Badrul Aini Medan Tahun 2015

Tabel 5. Distribusi Frekuensi Motivasi Ekstrinsik Bidan dalam pemberian susu formula pada bayi baru lahir di Rumah Sakit Badrul Aini Medan Tahun 2015

\begin{tabular}{ccc}
\hline Motivasi Ekstrinsik & Frekuensi & $\begin{array}{c}\text { Presentase } \\
\text { \% }\end{array}$ \\
\hline Baik & 3 & 15 \\
Kurang & 17 & 85 \\
\hline Jumlah & 20 & 100 \\
\hline
\end{tabular}

Berdasarkan tabel di atas, dapat dilihat motivasi Ekstrinsik mayoritas kurang sebanyak 17 orang $(85,0 \%)$ dan baik sebanyak 3 orang $(15,0 \%)$
Tabel 6. Distribusi Frekuensi Motivasi Ekstrinsik Bidan dalam pemberian susu formula pada bayi baru lahir berdasarkan jawaban di Rumah Sakit Badrul Aini Medan Tahun 2015

\begin{tabular}{|c|c|c|c|c|c|c|c|}
\hline \multirow{3}{*}{ No } & \multirow{3}{*}{ Pernyataan } & \multicolumn{4}{|c|}{ Jawaban } & \multirow{2}{*}{\multicolumn{2}{|c|}{ Jumlah }} \\
\hline & & \multicolumn{2}{|c|}{ ya } & \multicolumn{2}{|c|}{ Tidak } & & \\
\hline & & $\mathrm{F}$ & $\%$ & $\mathrm{f}$ & $\%$ & $\mathrm{~F}$ & $\%$ \\
\hline 6 & $\begin{array}{l}\text { Bidan memberikan susu } \\
\text { formula kepada bayi karena } \\
\text { adanya pengalaman dari } \\
\text { anak sebelumnya. }\end{array}$ & 23 & 41,1 & 33 & 58,9 & 20 & 100 \\
\hline 7 & $\begin{array}{l}\text { Bidan memberikan susu } \\
\text { formula kepada bayi karena } \\
\text { adanya reward dari produsen } \\
\text { susu formula. }\end{array}$ & 34 & 60,7 & 22 & 39,3 & 20 & 100 \\
\hline 8 & $\begin{array}{l}\text { Bidan memberikan susu } \\
\text { formula kepada bayi agar } \\
\text { bidan mendapatkan pujian } \\
\text { dari keluarga bayi. }\end{array}$ & 28 & 50,0 & 28 & 50,0 & 20 & 100 \\
\hline 9 & $\begin{array}{l}\text { Bidan memberikan susu } \\
\text { formula kepada bayi agar } \\
\text { bidan mendapatkan bonus } \\
\text { dari rumah sakit. }\end{array}$ & 17 & 30,4 & 39 & 69,6 & 20 & 100 \\
\hline 10 & $\begin{array}{l}\text { Bidan memberikan susu } \\
\text { formula kepada bayi untuk } \\
\text { mendapatkan tambahan } \\
\text { penghasilan untuk keluarga }\end{array}$ & 14 & 25,0 & 42 & 75,0 & 20 & 100 \\
\hline
\end{tabular}

5. Pemberian Susu Formula di Rumah Sakit Ibu dan Anak Badrul Aini Medan Tahun 2015.

Pemberian susu formula di Rumah Sakit Ibu dan Anak Badrul Aini Medan, dilihat dari hasil jawaban responden dalam pemberian susu formula., maka digunakan kuesioner yang berisikan 20 pernyataan yang dapat dilihat hasilnya pada tabel 7 berikut:

Tabel 7. Distribusi Frekuensi Pemberian (Proses bagaimana cara, pembuatan) susu formula pada bayi baru lahir di Rumah Sakit Badrul Aini Medan Tahun 2015

\begin{tabular}{ccc}
\hline $\begin{array}{c}\text { Pemberian Susu } \\
\text { Formula }\end{array}$ & Frekuensi & Presentase \% \\
\hline Baik & 20 & 100 \\
Kurang & 0 & 0 \\
\hline Jumlah & 20 & 100 \\
\hline
\end{tabular}

Berdasarkan tabel di atas, dapat dilihat pemberian susu formula pada bayi baru lahir mayoritas baik sebanyak 20 orang (100\%) dan kurang sebanyak 0 orang ( $0 \%)$. 
Tabel 8. Distribusi Frekuensi Pemberian (Proses bagaimana cara, pembuatan) susu formulapada bayi baru lahir di Rumah Sakit Badrul Aini Medan Tahun 2015

\begin{tabular}{|c|c|c|c|c|c|c|c|}
\hline \multirow{3}{*}{ No } & \multirow{3}{*}{ Pernyataan } & \multicolumn{4}{|c|}{ jawaban } & \multirow{2}{*}{\multicolumn{2}{|c|}{ Jumlah }} \\
\hline & & \multicolumn{2}{|c|}{$\mathrm{Ya}$} & \multicolumn{2}{|c|}{ tidak } & & \\
\hline & & $\mathrm{f}$ & $\%$ & $\mathrm{f}$ & $\%$ & $\mathrm{~F}$ & $\%$ \\
\hline 11 & $\begin{array}{l}\text { Bidan dalam memberikan susu formula kepada bayi } \\
\text { dengan melihat jenis susu terlebih dahulu }\end{array}$ & 40 & 71,4 & 16 & 28,6 & 20 & 100 \\
\hline 12 & $\begin{array}{l}\text { Bidan dalam memberikan susu formula kepada bayi } \\
\text { sesuai dengan usia bayi }\end{array}$ & 24 & 42,9 & 32 & 57,1 & 20 & 100 \\
\hline 13 & $\begin{array}{l}\text { Bidan dalam memberikan susu formula kepada bayi } \\
\text { dengan melihat indikasi pada bayi terlebih dahulu }\end{array}$ & 12 & 21,4 & 44 & 78,6 & 20 & 100 \\
\hline 14 & $\begin{array}{l}\text { Bidan dalam memberikan susu formula kepada bayi } \\
\text { dengan mencuci botol dot terlebih dahulu }\end{array}$ & 33 & 58,9 & 23 & 41,1 & 20 & 100 \\
\hline 15 & $\begin{array}{l}\text { Bidan dalam memberikan susu formula kepada bayi } \\
\text { dengan mencuci tangan terlebih dahulu }\end{array}$ & 32 & 57,1 & 24 & 42,9 & 20 & 100 \\
\hline 16 & $\begin{array}{l}\text { Bidan dalam memberikan susu formula kepada bayi } \\
\text { dengan memeriksa suhu susu terlebih dahulu }\end{array}$ & 39 & 69,6 & 17 & 30,4 & 20 & 100 \\
\hline 17 & $\begin{array}{l}\text { Bidan dalam memberikan susu formula kepada bayi } \\
\text { dengan menyentuh mulut bayi dengan dot terlebih } \\
\text { dahulu. }\end{array}$ & 45 & 80,4 & 11 & 19,6 & 20 & 100 \\
\hline 18 & $\begin{array}{l}\text { Bidan dalam memberikan susu formula kepada bayi } \\
\text { dengan frekuensi } 2 \text { jam sekali }\end{array}$ & 16 & 28,6 & 40 & 71,4 & 20 & 100 \\
\hline 19 & $\begin{array}{l}\text { Bidan dalam memberikan susu formula kepada bayi } \\
\text { dengan takaran susu dan air mencapai } 60 \mathrm{ml}\end{array}$ & 36 & 64,3 & 20 & 35,7 & 20 & 100 \\
\hline 20 & $\begin{array}{l}\text { Bidan dalam memberikan susu formula kepada bayi } \\
\text { dengan menyendawakan bayi selesai minum susu }\end{array}$ & 43 & 76,8 & 13 & 23,2 & 20 & 100 \\
\hline
\end{tabular}

\section{PEMBAHASAN}

1. Motivasi Bidan dalam Pemberian Susu Formula di Rumah Sakit Ibu dan Anak Badrul Aini Medan Tahun 2015.

Dari hasil penelitian didapatkan bahwa sebanyak 15 orang $(75.0 \%)$ bidan yang mempunyai motivasi baik sedangkan yang mempunyai kategori motivasi kurang sebanyak 5 orang (25.0\%). Dalam hal ini penulis berasumsi bahwa yang mempengaruhi motivasi bidan dikarenakan oleh faktor Instrinsik yang sebesar 18 orang $(90.0 \%)$.

2. Motivasi Instrinsik dalam Pemberian Susu Formula di Rumah Sakit Ibu dan Anak Badrul Aini Medan Tahun 2015.

Mayoritas responden menjawab Iya dalam pemberian susu formula sebanyak 18 orang $(90.0 \%)$, dan responden yang menjawab tidak sebanyak 2 orang $(10.0 \%)$.

Pemberian susu formula ini diberikan karena banyak faktor yang mempengaruhi antara lain ibu dan bayinya.

Teori ini mengatakan bahwa bidan bergerak atau mengambil tindakan Serangkaian kondisi intrinsik, isi pekerjaan (job content) yang apabila ada dalam pekerjaan tersebut akan menggerakkan tingkat motivasi yang kuat sehingga dapat menghasilkan kerja yang baik. Jika kondisi tersebut tidak ada, maka tidak akan ada timbul rasa ketidakpuasan yang berlebihan. Faktor-faktor dari rangkaian ini disebut motivator.

Faktor yang meliputinya adalah sebagai berikut: 1.Prestasi, 2.Pengakuan, 3.Tanggung jawab, 4.Kemajuan,5.Pekerjaan itu sendiri,6.Kemungkinan berkembang. Model Herzberg pada dasarnya mengasumsikan bahwa kepuasan bukanlah konsep yang berdimensi satu. Penelitiannya menyimpulkan bahwa diperlukan dua kontinum untuk menafsirkan kepuasan kerja secara tepat (Satrianegara. 2012.hlm.65).

Menurut Taufik 2007, faktor-faktor yang mempengaruhi motivasi instrinsik yaitu :

1. Kebutuhan (need) yaitu seseorang melakukan aktivitas (kegiatan) karena adanya faktot-faktor kebutuhan baik biologis mauupun psikologis.

2. Harapan (Expectancy) yaitu Seseorang dimotivasi oleh karena keberhasilan dan adanya harapan keberhasilan bersifat pemuasan diri seseorang.Keberhasilan dan harga diri meningkat dan menggerakan seseorang kearah pencapaian tujuan. 3. Minat adalah suatu rasa lebih suka dan rasa keinginan pada suatu hal tanpa ada yang menyuruh.

Menurut Walgito (2004), bahwa motivasi itu mempunyai 3 aspek, yaitu aspek pertama keadaann terdorong dalam diri organisme, yaitu kesiapan bergerak karena kebutuhan, misalnya kebutuhan jasmani karena keadaan lingkungan, atau karena keadaan mental seperti berpikir dan ingatan. Aspek kedua perilaku yang timbul dan terarah karena keadaan ini, dan aspek ketiga goal atau tujuan yang dituju oleh perilaku tersebut (Khairani,2013).

Sama halnya dengan Penelitian yang dilakukan oleh Rena dengan judul Gambaran Motivasi Bidan Dalam pemberian susu formula pada BBL di Wilayah Puskesmas Kediri Kabupaten Pekalongan Tahun 2012 yaitu diketahui bahwa lebih dari separuh bidan mempunyai motivasi tinggi yaitu 18 orang $(57,7 \%)$ dalam pemberian susu formula pada BBL yang dikarenakan faktor lingkungan dan keadaan ibu dan bayi. 
Menurut asumsi peneliti bahwa tidak ada kesenjangan antara teori dengan hasil penelitian karena motivasi bidan mayoritas baik yang didukung oleh motivasi instrinsik salah satunya dipengaruhi oleh kebutuhan baik kebutuhan bagi bayi maupun kebutuhan si ibu.

3. Motivasi Instrinsik dalam Pemberian Susu Formula di Rumah Sakit Ibu dan Anak Badrul Aini Medan Tahun 2015.

Mayoritas responden menjawab Iya dalam pemberian susu formula sebanyak 3 orang (15.0\%), dan responden yang menjawab tidak sebanyak 17 orang $(85.0 \%)$.

Pemberian susu formula ini diberikan karena banyak faktor yang mempengaruhi.

Motivasi ekstrinsik adalah kebalikan dari motivasi instrinsik. Motivasi ekstrinsik adalah motif-motif yang aktif dan berfungsi karena adanya perangsang atau pengaruh dari orang lain sehingga seseorang berbuat sesuatu (Djamarah, 2002).

Motivasi ekstrinsik adalah motif-motif yang aktif dan berfungsi karena adanya perangsang dari luar.

Beberapa hal yang dapat menimbulkan motif ekstrinsik yaitu penyesuaian tugas dan minat, perencanaan yang penuh variasi, respons, kesempatan untuk menyesuaikan tugas pekerjaan, dan adanya kegiatan yang menarik untuk memenuhi kebutuhan (Uno,2012).

Menurut Handoko (2006) faktor ektrinsik adalah faktor yang berasal dari luar yang merupakan pengaruh dari orang lain atau lingkungan. Motivasi ini timbul sebagai akibat pengaruh dari luar individu, apakah adanya ajakan, suruhan, atau paksaan dari orang lain, sehingga dengan keadaan demikian seseorang mau melakukan suatu kegiatan. Dan menurut Taufik 2007, faktor-faktor yang mempengaruhi motivasi ekstrinsik adalah :

1. Lingkungan adalah tempat dimana seseorang tinggal. Lingkungan dapat mempengaruhi seseorang sehingga dapat termotivasi untuk melakukan sesuatu.Selain keluarga, lingkungan juga mempunyai peran yang besar dalam memotivasi seseorang dalam merubah tingkah lakunya. Dalam sebuah lingkungan yang hangat dan terbuka, akan menimbulkan rasa kesetiakawanan yang tinggi.

2. Imbalan yaitu Seseorang dapat termotivasi karena adanya suatu imbalan sehingga orang tersebut ingin melakukan sesuatu.

3. Dorongan keluarga Yaitu Dukungan dan dorongan dari anggota keluarga seperti suami, orang tua, dan teman semakin menguatkan motivasi seseorang untuk memberikan sesuatu yang terbaik. Dorongan positif yang diperlukan akan menimbulkan kebiasaan yang baik pula.

Peneliti berpendapat bahwa dari hasil penelitian ternyata faktor motivasi ekstinsik tidak mempengaruhi bidan dalam pemberian susu formula pada bayi baru lahir di Rumah Sakit Ibu dan Anak Badrul Aini Medan.
4. Pemberian (Proses, bagaimana cara pembuatan) Susu Formula di Rumah Sakit Ibu dan Anak Badrul Aini Medan Tahun 2015.

Dari hasil penelitian didapatkan data pemberian susu formula seluruhnya memiliki kategori baik sebanyak 20 orang (100.0\%). Dalam hal ini penulis berasumsi bahwa faktor dalam pemberian susu formula yang mempengaruhi yaitu pemilihan, pembuatan, dan frekuensi susu formula tersebut. Dengan mengikuti prosedur pemberian susu formula sesuai dengan faktor yang mempengaruhi diatas.

Menurut Depkes (2009) sebagai seorang bidan dalam memberikan asuhan pada bayi baru lahir terutama, pada bayi yang mempunyai indikasi tidak bisa mendapatkan ASI. Dalam proses memberikan susu formula bidan harus sesuai dengan prosedur yang telah dianjurkan sesuai dengan asuhan pada neonatus (Amiruddin.2013.hlm.31).

Menurut teori Ade (2011) Pemberian susu formula dikatakan baik apabila dalam proses persiapannya sesuai dengan prosedur yang telah disesuaikan dan diteliti,yang terdiri dari bagaimana takaran, pemilihan, jenis susu, serta hagien dalam pembuatan susu formula.

Maka dalam hal ini diperoleh asumsi bahwa dalam memberikan susu formula pada bayi baru lahir sesuaikan dengan prosedur, karena apabila tidak sesuai akan mengakibatkan diare, terganggunya sistem pencernaan, alergi pada bayi baru lahirt. Oleh karena itu setiap tenaga kesehatan selalu dibekali pengetahuan dan keterampilan dalam memberikan asuhan dan penkes kepada masyarakat tentang asuhan neonatus, terutama dalam penanganan bayi baru lahir pasca pulang dari rumah sakit.

\section{KESIMPULAN}

1. Motivasi Dalam Pemberian Susu Formula Pada Bayi Baru Lahir Di Rumah Sakit Badrul Aini Medan Tahun 2015, mayoritas memiliki motivasi baik sebanyak 15 orang.

2. Motivasi instrinsik Bidan Dalam Pemberian Susu Formula Pada Bayi Baru Lahir Di Rumah Sakit Badrul Aini Medan Tahun 2015, mayoritas memiliki motivasi baik sebanyak 18 orang.

3. Motivasi ekstrinsik Bidan Dalam Pemberian Susu Formula Pada Bayi Baru Lahir Di Rumah Sakit Badrul Aini Medan Tahun 2015, mayoritas memiliki motivasi kurang sebanyak 17 orang.

4. Pemberian ( Pemilihan, proses pembuatan, dan frekuensi) Susu Formula Pada Bayi Baru Lahir Di Rumah Sakit Badrul Aini Medan Tahun 2015, mayoritas memiliki motivasi baik sebanyak 20 orang.

\section{SARAN}

1. Bagi Rumah Sakit

Diharapkan kepada management rumah sakit untuk lebih memberikan pelatihan-pelatihan 
tentang bagaimana mengatasi agar menurunnya angka pemberian susu formula, agar lebih terlaksananya program ASI ekslusif.

2. Bagi Pelayanan

Diharapkan kepada setiap tenaga kesehatan khususnya bidan agar lebih memperhatikan dalam memberikan pelayanan kesehatan pada ibu-ibu yang memiliki bayi baru lahir khususnya dalam pemberian susu formula.

3. Perkembangan ilmu kebidanan

Diharapkan pada tenaga kesehatan khususnya bidan. Lebih cerdas dalam pemberian susu formula terutama dalam hal adanya motivasi instrinsik yang meliputi kebutuhan, harapan, dan minat.Serta tidak hanya mementingkan faktor ekstrinsik yang meliputi lingkungan, Imbalan, dan dorongan keluarga saja.

\section{DAFTAR PUSTAKA}

Anoraga,P. (2009). Psikologi Kerja. Edisi V. Jakarta: Rineka Cipta.

Anonim.R. (2012). PeningkatanPemberian ASI pada Wanita Bekerja.Jakarta :Salemba

Amiruddin.(2010). Promosi Susu Formula Menghambat ASI. Jakarta. TIM

Depkes, (2012).Profil Kesehatan Provinsi Sumatera Utara Tahun 2012. www.depkes.go.id. Tanggal 6 Maret 2014. Jam 22.45 WIB.

Hidayat, A.(2011).Metode Penulisan Kebidanan dan Teknik Analisis Data. Jakarta: Salemba Medika.

Jurdawanto, (2012).Peranan Bidan dalam Asuhan Neonatus. Yogyakarta: AswajaPressindo.

KBBI, (2011). KamusBesar Bahasa Indonesia.Jakarta :Salmba Media

Machfoedz, I.(2009). Metodologi Penulisan Bidang Kesehatan, Keperawatan, Kebidanan, Kedokteran. Yogyakarta: Fitramaya.
Maryunani.A. (2012).Inisiasi MenyusuiDini, ASI Ekslusif dan ManajemenLaktasi.Jakarta :TIM

Notoatmodjo, S.(2010). Metodologi Penulisan Kesehatan.Jakarta:Rineka Cipta

Prawirohardjo, S. (2008).Ilmu Kebidanan. Jakarta: PT Bina Pustaka Sarwono Prawirohardjo.

Rukiyah, A.Y., Yulianti, L.,Liana, M. (2011). AsuhanKebidanan Bayi dan balita. Jakarta: TIM.

Saleha.S. (2009).Motivasi Kesehatan Pelayanan. Jakarta: Salemba Medika.

Sardiman, (2011).Interaksi \& Motivasi Belajar Mengajar. Edisi I. Jakarta :Rajawali

Satrianegara, F.(2012).Buku Ajar Organisasi Dan Manajemen Pelayanan Kesehatan Serta Kebidanan. Jakarta: Salemba Medika.

Siti, W. Hesty, R., Anita, (2007).Perawatan masa Neonatus.Yogyakarta :: Fitramaya.

Soemarwoto, (2013).Buku Ajar Asuhan Kebidanan Neonatus Normal.Jakarta:EGC. (2012).Datadan Informasi Kesehatan Provinsi Sumatera Utara,Jakarta : Kementrian Kesehatan Republik Indonesia.

Taufik, M. (2007).Prinsip-Prinsip Promosi Kesehatan Dalam Bidang Keperawatan Untuk Perawat Dan Mahasiswa Keperawatan.Jakarta :Infomedia.

Thimothy A, (2008). Motivasi dan Interaksi dalam Pelayanan Kebidanan. Jakarta:Salemba Medika.

Uno, H. (2014). Teori Motivasi Dan Pengukurannya.Jakarta :Bumi Aksara.

UNICEF Indonesia, (2012).Ringkasan Kajian Kesehatan Ibu dan Anak.www.unicef.org/indonesia/. Tanggal 6 Maret 2014. Jam 16.00 WIB.

Wikipedia, (2012). Pengertian Bidan. id.wikipedia.org/wiki/bidan. Tanggal 12 April 2014. Jam 23.00 WIB.

World Health Organization, (2010).WHO Technical Consultation on Postpartum and Postnatal Care. 